\title{
The Therapeutic Window for Oxygen
}

Extracorporeal membrane oxygenation (ECMO) is used as a rescue therapy for patients unable to achieve acceptable physiologic status despite maximum support. In patients with severe ARDS or pediatric ARDS, along with preserved cardiac function, venovenous (VV) ECMO is a therapeutic option to support gas exchange and minimize ventilatorinduced lung injury while treating the patient's underlying condition. In 2017 Barbaro et al $^{1}$ published a review of neonatal and pediatric data from the Extracorporeal Life Support Organization (ELSO) registry. Between 2009 and 2015, a total of 21,907 reported ECMO cases had survival to hospital discharge of $61 \%$. For the 9,280 subjects considered to be in the pediatric group (age $29 \mathrm{~d}$ to $17 \mathrm{y}$ ), survival to discharge was $60 \%$ in the respiratory cohort, $57 \%$ for cardiac subjects, and $43 \%$ in extracorporeal cardiopulmonary resuscitation cases. The same report highlighted an increased proportion of pediatric respiratory failure patients treated with VV ECMO compared with venoarterial ECMO; in $2009,41 \%$ of cannulations were $\mathrm{VV}$, which increased to $59 \%$ by $2015 .{ }^{1}$

One of the most important questions surrounding the use of VV ECMO is how to maximize lung recovery. The 2017 ELSO adult guidelines ${ }^{2}$ recommend the use of "lung rest" settings regardless of whether the patient is on venoarterial or VV ECMO. Typical rest settings include long inspiratory time, low plateau pressure $\left(<25 \mathrm{~cm} \mathrm{H}_{2} \mathrm{O}\right)$, low $\mathrm{F}_{\mathrm{IO}_{2}}(<0.30)$, and titrated PEEP. This post-cannulation version of lung protection is well described, but there is considerable variability in practice. In a 2014 survey of ELSO centers, ${ }^{3}$ the majority (77\%) reported lung rest to be the primary goal of mechanical ventilation during ECMO. However, only $81 \%$ of participating centers reported using tidal volumes $\leq 6 \mathrm{~mL} / \mathrm{kg}$, including $34 \%$ who used ultraprotective tidal volumes $\leq 4 \mathrm{~mL} / \mathrm{kg}$. It stands to reason that, if it is important to avoid ventilatorinduced lung injury prior to cannulation, maintaining lungprotective ventilation during VV ECMO is a critical management strategy.

In this issue of Respiratory CARE, Friedman et $\mathrm{al}^{4}$ contribute an article reporting on their multicenter retrospective cohort study including subjects ages $14 \mathrm{~d}$ to $18 \mathrm{y}$ treated

Dr Rettig discloses a relationship with Dräger Medical.

Correspondence: Jordan S Rettig MD, Department of Anesthesiology, Critical Care and Pain Medicine, Division of Critical Care Medicine, Boston Children's Hospital, 300 Longwood Avenue, Bader 634, Boston, MA 02115. E-mail: jordan.rettig@childrens.harvard.edu.

DOI: $10.4187 /$ respcare.07704 with VV ECMO between 2011 and 2016. Overall survival to ICU discharge was $68 \%$. They noted variability in mechanical ventilator practices, though there was a clear trend toward the use of lung-protective settings. The key finding was that no ventilator parameter was associated with mortality except for $\mathrm{F}_{\mathrm{IO}_{2}}$. The authors rigorously controlled for underlying disease, severity of illness, ventilator settings,

\section{See the Original Study on Page 271}

and ECMO settings when evaluating the impact of $\mathrm{F}_{\mathrm{IO}_{2}}$. The clearest illustration of this impact comes in Figure 2, a scatter plot of the $\mathrm{S}_{\mathrm{pO}_{2}}$ and ventilator $\mathrm{F}_{\mathrm{IO}_{2}}$ during ECMO. The points were divided into quadrants based on high or low $\mathrm{S}_{\mathrm{pO}_{2}}$ and high or low $\mathrm{F}_{\mathrm{IO}_{2}}$, with high defined as $\mathrm{S}_{\mathrm{pO}_{2}}>85 \%$ and $\mathrm{F}_{\mathrm{IO}_{2}}>0.50$. Survival to ICU discharge was significantly different based on quadrant $(P=.002)$. As expected, the high $\mathrm{S}_{\mathrm{pO}_{2}} /$ low $\mathrm{F}_{\mathrm{IO}_{2}}$ group had the highest survival at $81 \%$. What is particularly striking was that the high $\mathrm{S}_{\mathrm{pO}_{2}} /$ high $\mathrm{F}_{\mathrm{IO}_{2}}$ group showed diminished survival at $60 \%{ }^{4}$

Critical care providers have been increasingly aware of the harmful effects of high concentrations of inspired oxygen. As early as the 1940s, clinicians recognized an association between oxygen levels and retinopathy of prematurity. ${ }^{5}$ It has been demonstrated in the adult literature and confirmed in a pediatric study that hyperoxia is associated with increased ICU mortality following resuscitation from cardiac arrest. ${ }^{6,7}$ There is also evidence that hyperoxia has adverse effects on neurologic outcomes in traumatic brain injury. ${ }^{8}$ In the respiratory literature, it is well documented that using high levels of oxygen results in reactive oxygen species and tissue damage. It also results in absorption atelectasis, which can ultimately lead to ongoing alveolar injury.

Most lung-protective strategy guidelines include the use of PEEP for alveolar recruitment and tolerance of oxygen saturations between $88 \%$ and $92 \%$. The purported rationale is to minimize exposure to supplemental oxygen and the potential for oxygen-mediated lung injury. While high concentrations of oxygen have demonstrated pulmonary toxicity, there is little discussion in the literature about the potential risks of oxygen at what are typically considered non-toxic concentrations. Specifically, the dose-response effect of lower oxygen concentrations has not been extensively studied. The current work implies that the therapeutic window of oxygen may be much narrower than previously assumed. 
The work of Friedman et $\mathrm{al}^{4}$ highlights the importance of meticulous management of every component of the lungprotective approach, including $\mathrm{F}_{\mathrm{IO}_{2}}$. It reminds us that the gap between survivor and nonsurvivor may be narrowed if $\mathrm{F}_{\mathrm{IO}_{2}}$ is no longer regarded as an "easy button," rather than a potent therapy with a specific therapeutic range. It remains an active point of debate whether higher pressure or oxygen is more toxic. In this particular patient cohort, with an average PEEP of $10 \mathrm{~cm} \mathrm{H}_{2} \mathrm{O}$, it is hard to argue that higher $\mathrm{F}_{\mathrm{IO}_{2}}$ was needed to combat otherwise unacceptably high ventilator settings. Instead, the data indicate that either our therapeutic goals for $\mathrm{S}_{\mathrm{pO}_{2}}$ may be inappropriately high, or we are choosing the wrong knob to turn, or both. While prospective studies of $\mathrm{F}_{\mathrm{IO}_{2}}$ management during VV ECMO are needed, it would be wise to treat oxygen with the same respect we have shown for pressure when considering lung protection. Currently the overall survival rate in pediatric ECMO patients is around $60 \%$. We cannot afford to miss any opportunity for improvement.

Jordan S Rettig

Department of Anesthesiology, Critical Care and Pain

Medicine

Division of Critical Care Medicine

Boston Children's Hospital

Boston, Massachusetts

\section{REFERENCES}

1. Barbaro RP, Paden ML, Guner YS, Raman L, Ryerson LM, Alexander $\mathrm{P}$, et al. ELSO member centers. Pediatric Extracorporeal Life Support Organization registry international report 2016. ASAIO J 2017;63(4): 456-463.

2. Extracorporeal Life Support Organization (ESLO). Guidelines for Adult Respiratory Failure v1.4. Aug 2017. Available at: https://www. elso.org/Resources/Guidelines.aspx. Accessed February 7, 2020.

3. Marhong JD, Telesnicki T, Munshi L, Del Sorbo L, Detsky M, Fan E. Mechanical ventilation during extracorporeal membrane oxygenation: an international survey. Ann Am Thorac Soc 2014;11(6):956961.

4. Friedman M, Barbaro R, Bembea M, Bridges B, Chima R, Kilbaugh T, et al. Mechanical ventilation in children on venovenous ECMO. Respir Care 2020;65(3):271-280.

5. Terry TL. Extreme prematurity and fibroblastic overgrowth of persistent vascular sheath behind each crystalline lens: I. Preliminary report. Am J Ophthalmol 1942;25(2):203-204.

6. Kilgannon JH, Jones AE, Shapiro NI, Angelos MG, Milcarek B, Hunter $\mathrm{K}$, et al. Association between arterial hyperoxia following resuscitation from cardiac arrest and in-hospital mortality. JAMA 2010;303(21): 2165-2171

7. Ferguson LP, Durward A, Tibby SM. Relationship between arterial partial oxygen pressure after resuscitation from cardiac arrest and mortality in children. Circulation 2012;126(3):335-342.

8. Davis DP, Meade W, Sise MJ, Kennedy F, Simon F, Tominaga G, et al. Both hypoxemia and extreme hyperoxemia may be detrimental in patients with severe traumatic brain injury. J Neurotrauma 2009;26 (12):2217-2223. 